\title{
O DIREITO COMO PESQUISA DO JUSTO
}

\section{LAW AS A RESEARCH OF FAIR}

...Buscai e achareis;

e o que busca acha...

(Mateus, VII: 7: 11).

Jeannette Antonios Maman*

\section{Resumo:}

A questão do justo e a resolução dos conflitos, no caminho da via investigativa fenomenológica de Martin Heidegger: Fenomenologia existencial do Direito.

Palavras-chave: Busca do Justo. Conflito. Transformação. Filosofia do Ser. Fenomenologia Existencial do Direito.

\begin{abstract}
:
This paper is an introduction to the study of iustum. The question was taken in account the social conflicts. The "way of the arriving thinker... by way and offway".
\end{abstract}

Keywords: Justice. Law Philosophy. Being Philosophy. Phenomenology. Original Truth.

1. O horizonte do sentido

Uma pessoa inteligente já se equivocou ao interpretar este título (Marcelo Leite a propósito de seu texto). ${ }^{1}$

Foi muito oportuno o uso da expressão em texto de Marcelo Leite, que me permitiu tomar, com muita liberdade, mas também com muito respeito, o exemplo que permite pôr à luz da clareira em um novo modo historiográfico, o conteúdo das palavras "justo" e "justiça".

Neste sentido, dedico este singelo artigo aos que compreendem equivocadamente parte de meu trabalho em Filosofia Jurídica na linha de pesquisa inaugurada por Aloysio Ferraz Pereira, ${ }^{2}$ que hoje atualizo, como fenomenologia existencial do Direito, ${ }^{3}$ segundo a via investigativa de Martin Heidegger. Este pensador não se

\footnotetext{
* Professora Doutora do Departamento de Filosofia do Direito da Faculdade de Direito da Universidade de São Paulo.

1 LEITE, Marcelo. Ciência: use com cuidado. Folha de S. Paulo, São Paulo, 19 out. 2008. Caderno Mais, p. 9.

2 PEREIRA, Aloysio Ferraz. Estado e direito na perspectiva da libertação: uma crítica segundo Martin Heidegger. Revista dos Tribunais, São Paulo, 1980.

3 MAMAN, Jeannette Antonios. Fenomenologia existencial do direito: crítica do pensamento jurídico brasileiro. São Paulo: Edipro, 2000.
} 
dedicou em especial à moral ou à ética, e sim ao que chamou de "um novo humanismo", por oposição à tradicional metafísica que de Aristóteles vai até Kant. O humanismo heideggeriano encontra sua melhor assertiva na injunção que desconsidera o despencar na subjetividade, que nos torna indiferentes e ausentes das questões sociais.

\section{Justificativa do retorno ao tema}

A investigação de novos questionamentos

A questão da busca do justo, com suas raízes históricas assentadas no pensamento grego, que tomamos como origem da Filosofia ocidental, tem razões na necessidade de um corte epistemológico, que dá consistência ao tema. Não o fazemos, entretanto, sem levar em consideração o Direito oriental, em algumas ligações, mas que fogem aos objetivos deste artigo.

Quem como eu foi educada na ação de compreender a cultura d'Os Livros como códigos de costumes há de entender que, embora a citação bíblica pareça indicar conteúdo religioso ao texto, este é um texto filosófico e histórico. A arte, seja em suas várias manifestações, também é "gancho" da formação de nossa geração, que amava os Beatles e os Rolling Stones, mas viveu a ditadura como aqueles que não tinham voz. Antonio Cândido fala da geração sem palavras. Muitos aprenderam com ele, a fala e a resistência intelectual. Vivemos o libertário 1968, nós no silêncio imposto pelo Poder da opressão, o mundo, na ação de se libertar e manifestar-se resoluto. Foi um lindo ano para mim.

Em recente Simpósio sobre ciência e literatura, no qual o Centro Interunidade de História da Ciência da USP prestava homenagem aos 90 anos do professor Antonio Candido, ${ }^{4}$ Simpósio este que tive a honra de organizar, na Comissão Executiva, e também participar como expositora, ao lado, entre outros, de Nicolau Sevcenko. Foi este caronovo-e-sempre-amigo, que lembrou a geração sem palavras, à que se referira Antonio Candido.

E, mais, lembrou-nos dos agentes de nosso tempo, como intencionalmente culpados (grifos nossos), já que se anunciam noções de alteração de nossa humanidade, por ações comprometidas com a ordem técnica. A noção é muito heideggeriana, no mesmo sentido da fenomenologia que se indicava em Husserl, é que, com os desvios de Heidegger, alimenta nossa linha de pesquisa, para a fenomenologia existencial do Direito.

Em nossa breve homenagem a Antonio Candido, aproveitamos a ocasião para também lembrar o Centenário de Machado de Assis, na referência ao conto Idéias

\footnotetext{
4 SIMPÓSIO CIÊNCIA E LITERATURA: duas visões do nosso tempo. Homenagem aos 90 anos do Professor Antonio Candido e aos 80 anos do Professor José Goldemberg.
} 
de canário. Assim, nossa reflexão crítica encaminha a questão para o horizonte que se pode ver dos limites das grades das gaiolas e as possibilidades despidas de limitações que permitem a vivência de experiências, na proximidade com um pensamento vitalista, longe das ideologias encobridoras. É como se disséssemos: primeiro a experiência, depois as idéias, apresentando um Machado heideggeriano, "avant-la-lettre".

Posições filosóficas

Há estudiosos em nosso departamento (Filosofia e Teoria do Direito) que pensam poder dar unidade aos estudos filosóficos, no que diz respeito ao ser humano, conciliando arte, religião e ciência.

Se as três manifestações da procura por compreensão dos modos de sua própria existência, dão uma "certa" unidade à constituição humana, é bem verdade que, nesta unidade há características próprias no interior de cada fenômeno cultural (artístico, cientifico ou religioso). E mais, os modos de manifestação dos fenômenos nem sempre podem ser separados com tanta clareza, pois "transitamos" entre a ocultação e o desvelamento (a separação por hífen é aqui necessária, de vez que não impedida) e a busca pelos caminhos que investigam, como ocupação, mas ao mesmo tempo, cuidado, decorrente da condição do humana de afetação pelo mundo e pelo ser-com-o-outro. Não negamos o poder emancipador da arte e da literatura, mas as religiões só se ligam à Filosofia Jurídica se forem pensadas como códigos de ética, enquanto prática social. Esta sim pode ser transformadora, quando rompe padrões ultrapassados.

\section{Conflito e busca de composição para a existência do ser-humano}

Toda indicação, como Heidegger chama às noções (e não-conceitos) recomendam o $\$ 7^{\circ}$ de Ser e Tempo, aos que, tardiamente, passam a admitir o "autor maldito", e então estudá-lo. Seguem a opinião de Richard Rorty que afirmava serem Heidegger e Wittgenstein os filósofos mais importantes do século XX. Isto dito na América do Norte! A carta sobre o humanismo é, talvez, o sopro poético da senectude. Elucida, ao seu tempo, a questão heideggeriana de um novo humanismo como ele se refere, por contraposição à metafísica tradicional. Ser e Tempo continua como um cipoal para os neófitos. Já indica a possibilidade de encontrar o que se oculta na interioridade dos fenômenos, pelo des-velar, pelo des-encobrimento.

A citação bíblica, muito provavelmente escrita em grego, uma vez que Mateus era reconhecido por sua cultura, já expressava o "método" para encontrar ("achar") como o caminho da busca, da procura do sentido que nos damos como horizonte. Método, aqui, não se refere ao que hoje se diz como "metodologia", mas encontra sua origem no grego, quando a tradução é caminho. 
Recorremos ao poeta espanhol Antonio Machado, em passagem que merece, pela sua densidade, muitas interpretações.

\section{Do poema Caminante:}

Caminante, no hay camino, se hace camino al andar. Al andar se hace camino y al volver la vista atrás se ve la senda que nunca se ha de volver a pisar, caminante no hay camino sino estelas en la mar.

De certo modo, este é um poema que guarda sentido heraclítico.

Nos mesmos rios entramos e não entramos nós somos e não somos. $^{5}$

Entretanto, mantemos nossos olhos no passado, que como afirma Heidegger caminha á nossa frente, no persistir do fluxo da existência. Embora os rios não sejam os mesmos e nós sejamos outros, o de-vir, o vir-a-ser é o que persiste.

Se o destino é um "fardo" da tradição histórica, abrir caminho é enfrentar, resoluto, a liberdade - de-ser. É a re-solução não como trilha de caminho marcado, mas a que segue rumo desconhecido. O conflito entre o que foi e o que será resolve-se em Heráclito:

O adverso é benéfico; a partir das diferenças, (nasce) o mais belo conjunto. ${ }^{6}$

O conflito e sua superação, como composição de harmonias (do mesmo modo que cores opostas se equilibram na sua disposição, exemplos de verde e vermelho) mantém o ânimo, "Stimming"7 no que diz respeito ao pensamento do jurista, para nos reconhecermos como seres livres. E ainda que não seja filosofia de concordância entre os estudiosos de Heidegger, penso que a liberdade é uma questão ou direção essencial no seu trabalho. E nada surge sem resistência e superação.

As almas mortas por Ares são mais puras que aquelas mortas em meio às doenças. ${ }^{8}$

Não se trata, entretanto, da liberdade "individual", mas ainda no campo jurídico, se considerarmos o "oficio" da técnica, precisamos compreendê-lo, não como atividade neutra, mas atividade transformadora, que nasce do caminhar pela historia da experiência humana, que deu conteúdo para a expressão justo e justiça. A liberdade jurídica assume aqui um questionamento. Assume a busca e a possibilidade do encontro.

5 DIELS, H. Die fragmente der Vorsokratiker Fragmento. 133 49. ed. Berlim: W. Kranz, 1934-54.

6 DK-Fragmento 116. 8. ed.

7 Id. Ibid.

8 CONCHE, Marcel. Heraclite-Fragments. Fragmento 033. 136. ed. Paris: PUF, 1986. 
Quando um dos capítulos da tese Fenomenologia Existencial do Direito se anuncia como busca do justo, ${ }^{9}$ quero dizer que a investigação do que se oculta na "suposta" neutralidade do "Direito" é a indicação do caminho próprio da "arte" do jurista. E a "justiça" é a obra de arte que se mostra. Não encontramos se não saímos à procura. Mas, se nos pomos a procurar é porque já encontramos.

Seria muita ingenuidade confundir "Direito" e "Justiça". Ou identificá-los. Alguns já entenderam muito mal o que trabalho, quando pensaram como Aristóteles que "só" é direito, o Direito Justo. Tratava-se aqui da da legitimidade na polis grega; Avança minha atividade, para além da política, e chega à filosofia como via investigativa.

No trajeto de coerência sempre se anunciam probabilidades, noção que vem com a teoria de Goffredo Silva Telles, e possibilidades, na esteira de um poder-ser heideggeriano que se apropria da liberdade como "essência da verdade." O homem é sua própria possibilidade, mas não pode "produzir-se" a si mesmo", ${ }^{10}$ já que o "tornar-se a si-mesmo" não é como "fabricar" um artefato, mas sim vencer e resistir às destinações que impedem o poder-ser, como ser-livre, na tragédia da impessoalidade, acobertada por "entulho" de tradições já mortas, mas ocultas na aparência do cotidiano, banalizadas naquilo que sempre foi e que não causa mais indignação.

Há na vida uma incerteza quântica, como na Teoria de Mestre Goffredo, que não confere, entretanto ao ser-humano o caráter de se submeter à determinação da atuação impensada, ao contrário, é porque nos espera o imprevisto, que devemos pensar mais.

Não reconhecer o "Direito" como "técnica" é nos impedirmos de superar a dominação feita com esta instrumentalidade. Recorremos à correspondência de Heidegger a Jean Palmier (1969) para citá-lo: ${ }^{11}$

Questionar a técnica é um caminho. Questionar a essência da técnica é construir uma relação livre com ela. Técnica não é a mesma coisa que essência da técnica.

Por causa da técnica, como por causa da estética, não preservamos o ser essencial da arte.

É sempre bom deixarmos uma palavra para o poeta, do mesmo modo como lembramos a passagem de Mateus.

Ali onde cresce o perigo, também cresce o que salva.

(Hölderlin)

Com recurso aos estudos de Heidegger, em sua busca dos originários, na obra dedicada a Parmênides, reservamos a conclusão que pode ser a síntese deste

\footnotetext{
9 MAMAN, Jeannette. Antonios. op. cit.

${ }^{10}$ PALMIER, Jean Towarnicki. Conversa com Heidegger. L'Express, n. 954, 20-26 de oct. 1969.

11 Id. Ibid.
} 
nosso trabalho, sustentando a pesquisa jurídica no sentido da filosofia do ser, quando a fenomenologia existencial é o caminho a ser seguido, fazendo-se ao andar e buscar.

Para pensarmos o ser não é necessário o aparecimento festivo na veste de uma erudição pretensiosa ou no aparato de estados raros e excepcionais, ao modo de uma submersão e excesso místicos num sentido mais profundo. Tudo o que é necessário é o simples despertar na proximidade de todo e qualquer ente em sua disposição e inaparência, despertar este que, repentinamente, vê que o ente "é".

(Martin Heidegger-Parmênides)

Notas explicativas: todas as tradições são de nossa responsabilidade, sendo que lembramos, aqui a tradução de Antonio Machado, para não restar dúvidas por pequenas diferenças idiomáticas:

Caminhante, não há caminho, o caminho se faz ao andar. Ao andar se faz o caminho e ao voltar o olhar para trás se vê a trilha que nunca se voltará a pisar, caminhante não há caminho senão o rasto espumante do mar.

Agradeço a colaboração de Osvaldo Seguel na recuperação do poema, e de sua autoria. Embora Clóvis Rossi já o houvesse citado em artigo do jornal Folha de S. Paulo, algumas vezes ele aparece sem referência de Autor.

São Paulo, setembro de 2008.

\section{Referências}

CONCHE, Marcel. Heráclite. Fragments. Paris: PUF, 1986.

HEIDEGGER, Martin. El ser y el tiempo. Traducción de José Gaos. México: Fondo de Cultura Económica, 2002.

Heráclito: a origem do pensamento ocidental. Lógica. A doutrina Heraclítica do lógos. Tradução de Márcia de Sá Cavalcante. Rio de Janeiro: Editora Relume Dumare, 1998.

. Parmenides. Transleted by André Schuwer and Richard Rojcewicz. USA: Indiana University Press, 1998. 
. Parmenides. Tradução de Sérgio Mário Wrublevski; Revisão da tradução, Renato Kirchner. Bragança Paulista: Editora Universitária São Francisco - EDUSF / Petrópolis: Editora Vozes, 2008.

. Ser e Tempo. Tradução de Márcia de Sá Cavalcante. Petrópolis: Editora Vozes, 1988.

DIELS, H. Die Fragmente der Vorsokratiker. 5. ed. e posteriores. Berlim: W. Kranz, 1934-1954. Fragmentos: $133\left(49^{\mathrm{a}}\right)$ e $116\left(8^{\mathrm{a}}\right)$.

MAMAN, Jeannette Antonios. Fenomenologia Existencial do direito. São Paulo: Edipro - Edições Profissionais, 2000.

Fenomenologia Existencial do direito. 2. ed. São Paulo: Editora Quartéis Lacem, 2003.

PALMIER, Jean; TOWARNICKI, Frédéric de. Conversa com Heidegger. L'Express, Paris, n. 954, 20/26 oct. 1969 .

PEREIRA, Aloysio Ferraz. Estado e direito na perspectiva da libertação: uma crítica segundo Martim Heidegger. São Paulo: Revista dos Tribunais, 1980. 